\title{
La Cançó de la croada contra els albigesos (1r quart del s. XIII) i el Tractat de Meaux-París (1228). Mimesi literària i constància jurídica de la desposessió d'Occitània
}

\author{
The Song of the Crusade against the Albigensians \\ (1st quarter of the 13th century) and the Treaty of Meaux-Paris (1228). Literary \\ mimesis and legal certainty of the dispossession of Occitania
}

VICENT MARTINES
martines@ua.es

Universitat d'Alacant - ISIC-IVITRA

IEC-RABLB

\begin{abstract}
Resum: En aquest article analitzem els mecanismes de la construcció del relat (oficial), des de diversos punts de vista, de la Croada contra els albigesos i l'expoli d'Occitània per França en el transcurs d'aqueixa cruel campanya militar (1r terç del segle XIII). Analitzarem dues fonts textuals que són testimonis d'excepció dels fets i de la construcció i la narració d'aqueix relat, a través de la mimesi historiogràfica en un cas, la Cancó de la Croada contra els albigesos, i, en l'altre, del formalisme d'un text jurídic (document històric, pròpiament dit) del més alt rang, el Tractat de Meux-París (1229), signat pels màxims representants de les dues contraparts. I també analitzarem qui es beneficia (i per què), en primera instància, dels efectes del Tractat.
\end{abstract}

Paraules clau: Cancó de la Croada contra els albigesos, Tractat de Meaux-París (1229), Batalla de Muret, Pere el Católico, Alfons de Poitiers, Lluís IX de França, Ramon VII de Tolosa, Historiografia medieval.

\begin{abstract}
In this article I analyze the technic behind the construction of the (official) story, from different points of view of the Crusade against the Catars and the dispossession of Occitania by the French Crown during the course of that cruel military campaign (1st third of the 13th century). I analyze two textual sources that are added value witness of the facts in order to make and to tell that story, through the historiographic mimesis in one case, the Song of the Crusade againts the Catars, and, in the other, the formalism of a legal text (historical document, proper) of the highest rank, the Treaty of Meux-Paris (1229), signed by the highest representatives of the two parties. And Il also analyze who benefits (and why), in the first instance, from the effects of the Treaty.
\end{abstract}

Keywords: Song of the Crusade againts the Catars, Treaty of Meaux-Paris (1229), Battle of Muret, King Peter The Catholic of Aragon, Alphons de Poitiers, King Louis IX of France, Raymund VII of Toulouse, Medieval Historiography

\footnotetext{
* Aquest estudi s'ha dut a terme en l'Institut Superior d'Investigació Cooperativa IVITRA [ISIC-IVITRA] (Programa per a la Constitució i Acreditació d'Instituts Superiors d'Investigació Cooperativa d'Excellència de la Generalitat Valenciana, Ref. ISIC/012/042), i en el marc dels projectes, xarxes i grups de recerca següents: «Variación y cambio lingüístico en catalán. Una aproximación diacrónica según la Lingüística de Corpus» (MICINUN, Ref. PGC2018-099399-B-100371); (IEC, Ref. PRO2018-S04-MARTINES); del Grup d'Investigació VIGROB-125 de la UA; la Xarxa de recerca en innovació en docència universitària «Lingüística de Corpus i Mediterrània intercultural: investigació educativa per a l'aplicació de la Lingüística de Corpu§s en entorns multilingües diacrònics. Aplicacions del Metacorpus CIMTAC» (Institut de Ciències de l'Educació de la UA, Ref. 4581-2018); i el Grup d'Investigació en Tecnologia Educativa en Història de la Cultura, Diacronia lingǘstica i Traducció (Universitat d'Alacant, Ref. GITE-09009-UA]).
} 
Vicent Martines. La Cançó de la croada contra els albigesos (1r quart del s. XIII) i el Tractat de Meaux-París (1228)

\section{La Cançó de la Croada contra els albigesos: mimesi i Història}

La Cançó de la Croada contra els albigesos ${ }^{1}$ ens aporta un testimoni excepcional d'aqueixa croada que va assolar Occitània i va ser una veritable guerra de conquesta i annexió en favor de la Corona francesa d'aqueixos senyorius tan rics i estratègicament situats al nord dels Pirineus i com a clau de l'arc de la Mediterrània. Al llarg de 9.582 versos alexandrins, aquest text ens reporta els esdeveniments de la croada (entre 1204 i 1219). Té dos autors, un de conegut, Guillem de Tudela, autor de la primera part, que consta dels 2.772 primers versos, distribuïts en 131 laisses (o cobles) d'alexandrins; aquestes laisses tenen un nombre de versos variable, tot i que no són gaire extenses (d'una mitjana d'una vintena de versos). Aquesta primera part de l'obra pren partit en favor dels croats. Un altre autor, anònim, és el responsable de la segona part. Aquesta, consta de 6.810 versos, distribuïts en 83 laisses (de la 132-214), que són molt més extenses que les de Tudela. Aquesta segona part, molt més rica i elaborada literàriament, pren partit clarament pels occitans. És una obra ben interessant pel perspectivisme o contrast de punts de vista que ens ofereix d'un mateix fet històric i mentre aquest s'està esdevenint. A més, ens remarca la gran importància que en la cultura cortés hom conferia a la literatura, en aquest cas com a instrument de propaganda (política i militar) (Martines \& Ensenyat 2003; Roquebert 2001; Zerner 1979).

És un text que ens reporta un testimoni d'excepció dels esdeveniments, coetani, quasi en temps real. Molts dels grans i petits senyors, sempre combatents contra l'invasor croat, queden reflectits amb els seus noms, llinatges i fets memorables. També hi compareixen els croats invasors i partidaris; també amb noms i llinatges. Sovint el text ens ofereix el punt de vista dels dos bàndols. Un bon exemple el tenim en el report de la batalla de Muret (1213) (Alvira Cabrer 2008, 2015, 2019). Aquesta va ser una decisiva com a derrota, de les forces occitanes $i$ de la seua valedora, la Corona d'Aragó; alhora, però, va ser victòria decisiva per als croats i per a la seua gran valedora i, al remat, principal beneficiària, la Corona francesa. Per a la Corona d'Aragó va ser una desfeta, sense pal liatius. En aquesta derrota, contra pronòstic, el valent rei Pere el Catòlic, va morir en combat. El bon rei d'Aragó, quan arriba a Muret, és presentat com el que era, el gran valedor dels occitans contra els francesos. La Cançó de la Croada ens reporta el moment en què el rei arriba a Muret, amb les seues forces, amb la senyera -en l'obra anomenada «l'oriflama». Sens dubte, un moment poderós, esperançador (vegeu Figura 1, el text de la qual correspon a la citació que tot seguit fem):

1 En les referències textuals seguisc l'edició de Martines \& Ensenyat (2003). Infra \5.2, parem més atenció a aquesta obra. En general, en aquest estudi, en fer referència a aquesta obra, direm Cançó de la Croada.

SCRIPTA, Revista internacional de literatura i cultura medieval i moderna, núm. 15 / juny 2020 / pp. 16 - 37 ISSN: $2340-4841 \cdot$ doi:10.7203/SCRIPTA.15.17552 

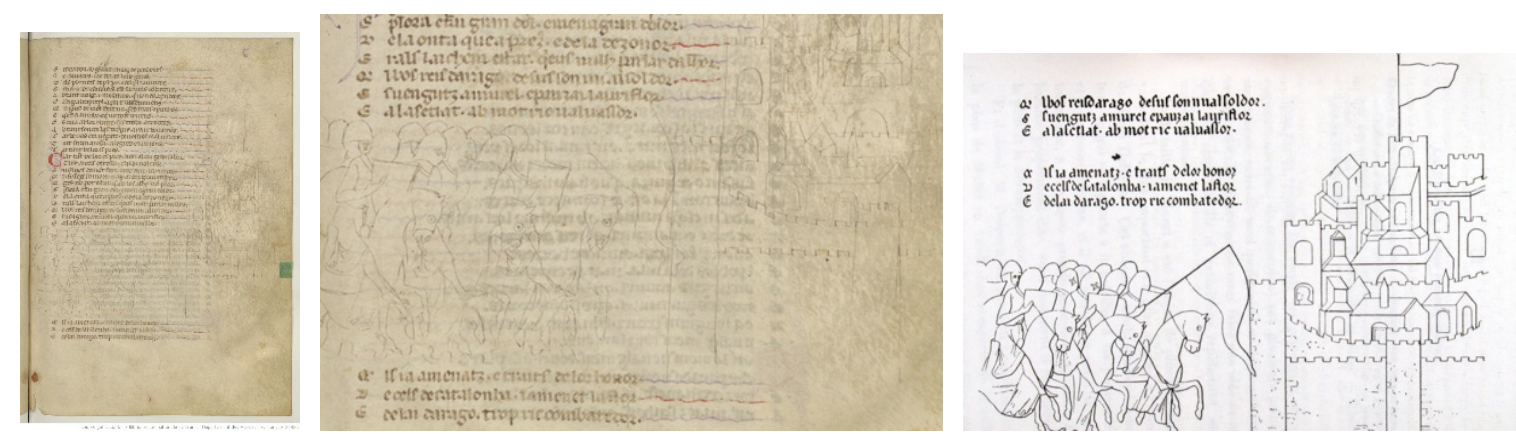

Figura 1: Cançó de la Croada contra els albigesos. Bibliothèque nationale de France, fr. 25425, f. 73, que ens reporta l'arribada de Pere el Catòlic, «el bon rei d'Aragó», a Muret, amb el seu seguici i forces, i la senyera (ací dita «l'oriflama»). Enmig, un detall per veure'n millor els versos citats ací i el dibuix que ens il lustra l'escena. A la dreta, una versió actual del mateix fragment que permet veure millor els perfils de les figures. $^{2}$

[1. 135]

$[\cdots]$

el bon rei d’Aragó, sobre el seu destrer de peratge,

vingué a Muret i hi planta l'oriflama;

i l'ha assetjat amb molts forts valvassor,

que els hi ha menats i trets dels seus dominis;

e dels de Catalunya hi portà la flor,

i d'Aragó molt poderós combatent.

Ell estava confiat en la superioritat numèrica dels seus efectius i, a més, havia participat de manera molt remarcable -segons com decisiva al seu torn- en la victòria de las Navas de Tolosa (1212) sobre les forces musulmanes, un enemic no gens fàcil (Cressier \& Salvatierra 2014). A Muret, la host croada havia quedar resclosa al no gaire gran ni tan inexpugnable castell de Muret, prop de Tolosa de Llenguadoc (Alvira Cabrer 2014). Els primers enfrontaments havien estat molt favorables per a la Corona d'Aragó. La Cançó de la Croada ens reporta els consells tinguts pel «bon rei d'Aragó» i pel cabdill de la croada, Simó de Montfort. Aquest, a més, reconeix als seus la seua gran preocupació per la situació tàctica i estratègica desfavorable en què es troben i que, a la fi, s'ho han de jugar a una eixida a camp obert, pràcticament desesperada. El text ens ho ofereix amb el que sembla un report (i «retransmissió» que sembla, a més, que siga realment en estil directe) tan ben descrit que podríem dir, en paraules de Quintilià (Quintilianus), «ut cerni videatur quam audir» el que hi va passat; ho podem veure i oir, quasi fins i tot sentir com si passés davant de nosaltres, amb una vívida potència

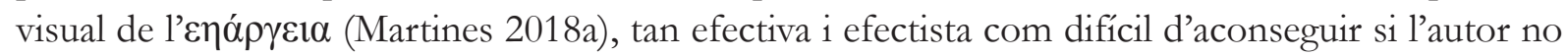

2 Vegeu, quant a aquesta versió actualitzada de la il lustració del ms: http://comminges.org/le-temps-de-la-bataillede-muret-12-septembre-1213/ [consulta: 20-02-2020.] 
Vicent Martines. La Cançó de la croada contra els albigesos (1r quart del s. XIII) i el Tractat de Meaux-París (1228)

és ben destre (en aquest cas som a la part anònima de l'obra, però més rica, diversa i avançada poèticament). Tot seguit transcrivim qualque passatge en què podem veure $i$ oir les intervencions dels dos caps -el rei Pere el Catòlic i Simó de Montfort- davant dels seus «estats majors» i un passatge de la batalla de Muret, crucial: la mort del rei Pere el Catòlic i la desbandada consegüent de les seues forces, que són masacrades pels croats:

\section{[1. 138]}

[...] després, a l'endemà, quan el sol lluïa, el bon rei d'Aragó $i$ tota la seua capitania anaren a parlamentar, fora, en un prat, i el comte de Tolosa i el de Foix igual, i el comte de Cumminge, amb bon cor i lleial, i molts altres barons i n'Huc el senescal, $i$ els burgesos de Tolosa i tots els menestrals.

I el rei parlà primer.

[1. 139]

El rei parlà primer, car ell sap bé parlar:

-«Senyors -féu-, escolteu què us vull explicar:

Simó [de Montfort, cap de la host croada] allà ha arribat i no se'n pot escapar; per això us vull assabentar que la batalla serà abans del capvespre i que vosaltres estigueu llestos per a manar; heu de saber-los gran colps ferir i donar; que si foren deu vegades més, els faríem transtornar!» $[\ldots]$

En això criden: «A les armes!» I se'n van tots a armar-se.

Fins a les portes cavalcaren, tant que els francesos les feren tancar;

i per enmig de la porta llançaren les llances, i dins i fora combateren peu a terra, $i$ es llançaren dards i llances, i grans colps es donaren; d'ambdues parts feren la seua sang vessar, que tota la porta podríeu veure fer-se vermella. Quan els de fora no pogueren dins entrar, dret cap a les tendes començaren a tornar; $[\ldots]$

Però Simó de Montfort féu per Muret cridar $[\ldots]$

I, quan foren fora, els comença a arengar: «Senyors barons de França, no us sé cap consell donar, sinó que tots hem arribat a en perill estar.

Tota aquesta nit no he fet més que reflexionar, i els meus ulls no han pogut dormir ni han pogut reposar; així en la meua meditació he pogut trobar que per aquest camí ens convindrà passar, 


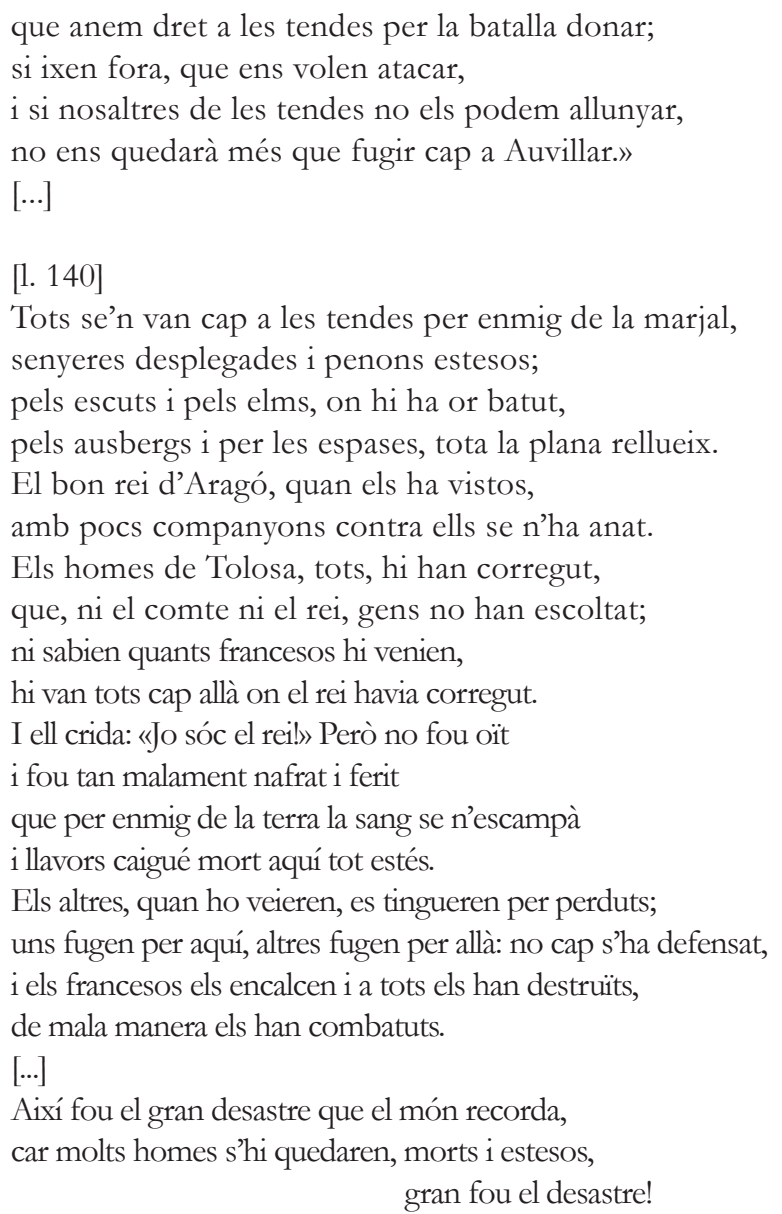

Les restes de les forces de Tolosa corren a refugiar-se darrere les fortes muralles de la ciutat. Poder arribar-hi esdevé un calvari: els croats els encalcen mortalment i, a més, han de travessar, sense quarter, el gran riu Garona. En arribar al clos de les muralles, les forces de la ciutat acorden pactar amb els invasors. Aquests, però, no semblen voler respectar ni vides, ni béns mobles i immobles, els mou la malvestat i la cobejança. A més, el text ens informa de les íntimes ni innegables vinculacions de la Corona francesa en la croada:

[1. 141]

Molt gran fou el desastre, el dol i la pèrdua quan el rei d'Aragó quedà mort i sangnant, i molts altres barons, i fou gran l'oprobi a tot el cristianisme i a tota la gent. Els homes de Tolosa, tots aïrats i dolguts, els que se n'escapoliren, que no hi caigueren, entraren a Tolosa, dins de les muralles.

En Simó de Montfort, alegre i joiós, ha conquerit el camp, del qual prengué molts guarniments; 
mostrà i reté a cadascun la seua part.

I el comte de Tolosa està aïrat i dolgut, i digué al Capítol -i això amb veu baixa-, que, al més aviat que puguen, facen pactes, que anirà al Papa a fer-li els seus clams: que en Simó de Montfort, per les seues males arts, l'ha foragitat de la seua terra amb cruels turments.

Després eixí de la seua terra, i els seus fills també; els homes de Tolosa, tristos i dolguts, pactaren amb Simó de Montfort i li feren juraments, $\mathrm{i}$ es reteren a l'església de bones maneres.

El cardenal féu dir, a París, igualment, al fill del rei de França que ja vingués corrents; que ell hi anés bonament $\mathrm{i}$ alegrement.

I entren a Tolosa tots junts, i s'empararen de la vila i de les cases, i s'allotjaren amb joia dins els palaus enrajolats.

Els homes de la vila digueren: «Siguem pacients, suportem el que Déu vol ben pacientment, que Déu ens pot ajudar, que és el nostre garant.» El rei del fill de França, que és de mal conformar, en Simó, el cardenal i en Folquet, tots alhora, digueren en secret que barrejarien tota la vila i que després pel foc cremant la passarien. En Simó pensa, que és dolent i cruel, que si destrueix la vila, això no serà la seua salvació, i que més val que en siga seu tot l'or i tot l'argent.

El papa Innocenci III, que s'havia distingit abans de ser elegit com un veritable especialista en dret, que havia estudiat a Bologna i havia de redreçar, ben format i relativament jove, les regnes de l'Església (Laveaga 2006; Smith 2015, 2019), va proclamar la croada contra l'heretgia càtara, en haver-los, prèviament, excomunicat. Abans, el Papa ja havia «destacat» com a llegat pontifici Pèire de Castellnou, de l'Abadia de la Fontfreda, prop de Narbona. Castellnou havia d'inquirir i reduir l'heretgia dels càtars, convèncer-los i tornar-los al solc de l'Església, o -com va passar a la fi- perseguir-los. Castellnou es va afanyar contra els càtars i, també, contra els que va considerar que era el context o «medi ambient» que els donava suport, especialment els caps dels senyorius. El Papa, a la fi, va llançar la Croada (Alvira Cabrer 2009, 2016b; Jiménez 2019; Lambert 1986; Laval 2000; Roquebert 2006a). (Vegeu Figura 2). 


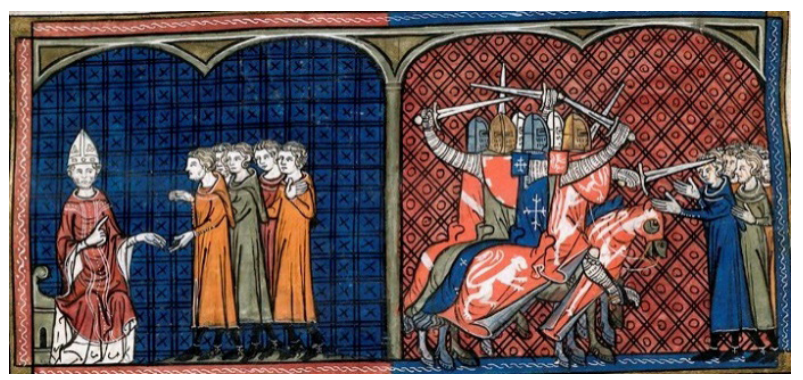

Figura 2: Innocenci III excomunica els càtars i l'exèrcit croat els ataca; el cavaller amb la sobrevesta vermella

i l'heràdica del lleó rampant és Simó de Montfort. Il luminació de la Chronique de Sant Denis, British Library, Royal 16 G VI f. 374v.

L'inicial cabdill de la croada va ser Simó IV de Montfort (ca. 1160/1165-Tolosa de Llenguadoc, 1218), V comte de Leicester (Lippiatt 2017, 2019; Roquebert 2010) amb la seua victòria a Muret i la presa de Tolosa que hem vist va reeixir en aconseguir per a França un èxit que, en el relat de la identitat francesa, roman a la mateixa alçada que la batalla de Bouvines (1212); aquesta sí que va ser lluitada en persona pel rei francès. D'aquesta manera, la Corona francesa es lliura d'«obstacles», al nord i al sud, per a la seua expansió (France 2015). Amb aquestes dues victòries el rei de França deixa de ser un primus inter pares i comença a construir la narrativa de la imatge d'una monarquia autoritària (Duby, 1990). De fet, Muret ha format part durant segles d'aquest relat de la construcció de la imatge nacional oficial de França, com ens ho demostra el tiratge d'un segell postal per celebrar el 790è aniversari de la batalla: forma part d'una sèrie el títol de la qual és molt simptomàtic en el sentit del relat de la imatge nacional francesa, «Les Grandes Heures de l'Histoire de France» (vegeu Figura 3).
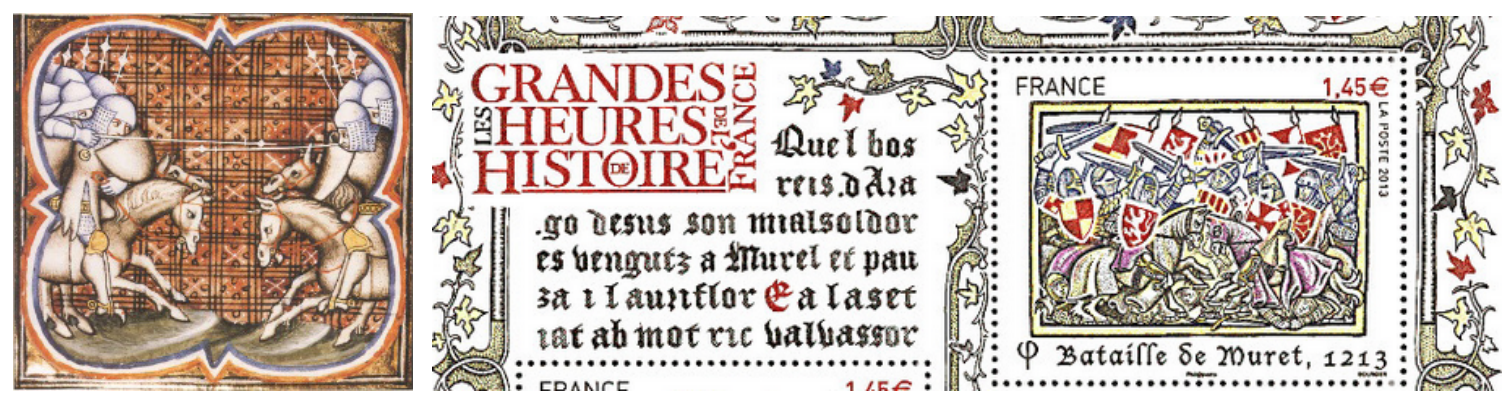

Figura 3. Primera imatge: batalla de Muret (1213), segons Anònim, Grandes Chroniques de France (Bibliothèque Nationale de France, Français 2813, f. 252v (s. XIV). Segona imatge: batalla de Bouvines (1214), en la mateixa obra i manuscrit, f. 253v. Segona imatge: segell postal que França va emetre en 2013 per celebrar el 790è aniversari de la batalla de Muret. El gravat representa la mort del «bos reis d'Aragó», i a dreta de la imatge hi ha els versos de la Cançó de la Croada que ja hem vist en la Figura 1 que ens reporten l'arribada del rei Pere el Catòlic a Muret. 
Vicent Martines. La Cançó de la croada contra els albigesos (1r quart del s. XIII) i el Tractat de Meaux-París (1228)

\section{E1 Tractat de Meaux-París (1229), la versió jurídica d'un relat de repressió i despossessió}

La Cançó de la Croada és molt detallada a relatar-nos que, després de la desfeta de Muret, la Croada va ser encara més un cúmul de desgràcies per als senyors occitans (Benito i Monclús 2019; Bordonove 1991). Hi va haver diversos intents i esperances al remat no infundades de poder revertir la croada, fer-la fugir o, almenys, pactar honrosament (Mussons 2015). Muret va definir i consolidar un front dissident transpirinenc (Jiménez 2015). Tanmateix, el poder de la Corona francesa i els seus recursos immensos van ser molt superiors i duradors, sobretot quan va poder operar lliurement sense l'amenaça de la Corona d'Aragó pel Sud, arran de la desfeta d'aquesta a Muret, i sense la formidable amenaça, pel nord, d'Anglaterra, el Sacre Imperi, Flandes, Brabant, Lorena i Limburg, per la desfeta d'aquesta coalició a Bouvines (Mace 2015, 2019; Marvin 2019). A més dels recursos militars esmerçats, sense reserves, per França, també cal afegir un altra gràcia de l'acció militar francesa -desgràcia per als poders occitans-, com ara la monolítica unitat d'acció política de la Corona francesa en pro de fer efectiva la seua decidida i unívoca voluntat per afermar les conquestes militars de la croada a fi de procurar-ne la incorporació legal al ple imperi i dret francès (Marvin 2008). Va ser clau la immediata activació de la preeminència del dret de França (Côtume de Paris) per sobre de l'ordenament jurídic o furs o usatges específics de cada senyoriu occità. Després de Muret, les despossessions, que ja s'havien donat des de l'inici mateix de la croada i abans de Muret -per exemple, a Carcassona, a Besiers-, es fan sistemàtiques (Roquebert 2006b; Cassignol 2006). Els senyors occitans passen a ser «faïdits», 'desposeïts». Han d'exiliar-se, molts a la Corona d'Aragó, des d'on no deixaran de participar en operacions de desestabilització i opcions de reconquesta contra els croats. Tot i això, la lògica dels esdeveniments, especialment determinada per l'aclaparadora magnitud dels recursos esmerçats per la Corona francesa, va fer que, tretze anys més tard de Muret, la Corona francesa imposara la firma del Tractat de Meaux-París (1229), que consuma la despossessió.

Pel Tractat de Meaux-París, el comte Ramon VII de Tolosa reconeixia la seua derrota davant Lluís IX de França, mentre que aquest li reconeixia i li restituïa la titularitat sobre el comtat de Tolosa (mutilat, però). El Tractat imposa condicions molt aspres. Ramon VII és el principal senyor occità i qui major oposició bèl lica havia presentat a les forces invasores, i encara en podria oposar. Ell i el seu pare, el comte Ramon VI, qui ja havia estat excomunicat pel Papa Innocenci III, havien estat desposseïts de tot el seu comtat, eren «faïdits»; de feu el comte Ramon VI havia mort com a tal. Tot i això, Tolosa encara podia ser un enemic formidable per a la croada. Tolosa tenia recursos immensos i exercia una influència certa en la identitat col lectiva antifrancesa. Encara que Tolosa no podia vèncer, per emparar-se'n de tot i consumar la conquesta total, la Corona francesa hauria d'esmerçar encara molts més recursos. Per això França força la firma del Tractat. Aquest esdevé una gran victòria de la Corona francesa en el procés de la seua penetració en Occitània (Paul 2007). 
Vicent Martines. La Cançó de la croada contra els albigesos (1r quart del s. XIII) i el Tractat de Meaux-París (1228)

Si atenem ad literam què ens diu el Tractat, i amb el context que hem establert, entendrem que aquest text legal de màxim nivell -signat pels màxims responsables de les dues contraparts, el rei de França, i el comte Ramon VII de Tolosa-, esdevé també un relat de la força latent que hom reconeix a Tolosa i de la relació tortuosa que s'establirà entre la Corona francesa i Tolosa i, per l'analogia que hom va fer d'aquest text legal quant a la resta d'Occitània, també els altres senyorius. En un altre estudi hem traduiit, per primera vegada aquest tractat a l'anglés, a fi de donar-lo a conèixer a una audiència més ampla que l'estrictament romanista (Martines 2020). Ara el presentem -per primera vegada- en traducció catalana del Tractat de París o de Meaux-París (1229) (Vegeu Figura 4).

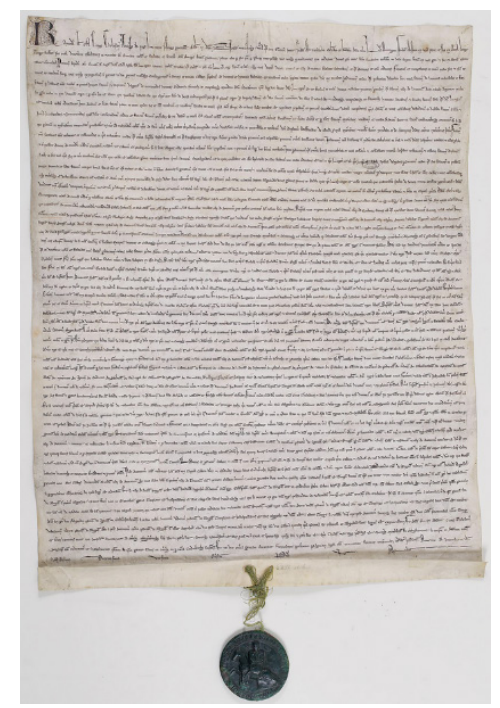

Figura 4: Ratificació del tractat per Ramon VII. Parés, Archives nationales, AE-II-230.

Patents de cartes del rei Lluís IX tot promulgant el tractat de pau conclòs amb Ramon VII, comte de Tolosa. París, abril de 1229. Ramon, fill del desaparegut comte de Tolosa, després d'haver persistit durant molt de temps en la seua excomunió (28-01-1226), en absència i rebel lia, va decidir, a instàncies del cardenal de Saint-Ange, llegat de la Santa Seu, implorar la pietat de l'Església i la del rei, tot subscrivint les condicions d'un tractat en vint-i-dos articles:

1. submissió a l'Església romana i fidelitat fins a la mort;

2. guerra contra els heretges, sense distinció de pares, vassalls i amics; depurarà la seua terra i ajudarà a purgar la del rei, i farà justícia dels heretges manifestats a través dels seus algutzirs;

3. prima de 2 marcs de plata durant dos anys i 1 marc a perpetuitat, per a qualsevol que capture un heretge convicte; per als heretges no manifestos, dissimuladors i creadors d'heretges, seguirà la voluntat del cardenal; 
4. defensa de l'Església i del clergat; defensa dels seus drets i privilegis; trencarà amb els excomunicats; s'apoderarà de la propietat d'aquells que no es reconcilien amb l'Església en un termini d'1 any;

5. obligatorietat de fer jurar als algutzirs el compliment d'aquestes normes, sots pena de confiscació dels seus béns;

6. nomenament d'algutzirs que no siguen jueus ni heretges, sinó catòlics reconeguts; les mateixes condicions per als recaptadors de la ciutat i els cobradors de peatges;

7. restitució total dels béns i drets de l'Església existents en el moment de l'entrada dels croats al país; per a altres propietats contencioses, es recorrerà als jutges ordinaris, al cardenal o als seus delegats;

8. compromís de pagar delmes i evitar que els cavallers i altres laics els recullen; en compensació pels danys causats, pagament de 10.000 marcs d'argent a comissaris designats pel cardenal o per l'Església romana; compensació a les abadies: Cîteaux, 2.000 marcs de plata; Clairvaux, 500; Grandselve, 1.000; Belleperche, 300; Candeil, 200; per a la fortificació de Castell-Narbonés i altres castells necessaris per a la seguretat de l'Església i del rei, 6.000 marcs; s'ha de pagar la suma total de 20.000 marcs en quatre anys;

9. destinar una quantitat de 4.000 marcs per a quatre Mestres en Teologia a raó de 50 marcs per any, dos Decretistes a 30 marcs, sis Mestres d'Arts Liberals a 20 marcs i dos residents de Gramàtica;

10. promesa de prendre la creu contra els sarraïns, com a penitència, immediatament després de l'absolució, d'anar a Terra Santa dins dels dos anys següents i romandre-hi cinc anys;

11. promesa de no prendre represàlies contra els membres de l'Església, dels reis Lluís VIII i Lluís IX i dels comtes de Montfort, i que hom els tractarà com a amics, a manera de reciprocitat;

12. la filla de Ramon VII serà lliurada al rei, qui, per dispensa de l'Església, es casarà amb un dels germans d'aquest;

13. el rei lliura a Ramon VII tot el bisbat de Tolosa, excepció feta de la terra del Mariscal; després de la mort del comte, Tolosa i el bisbat passaran al germà del rei; si aquest mor sense fills, els seus dominis tornaran a la corona, sense que els altres descendents o hereus de Ramon VII puguen reclamar-hi cap dret; el rei lliura al comte els bisbats d'Agen i Rodez i la part del bisbat per sota del Tarn, i la resta passarà al rei; el bisbat de Cahors, tret de la ciutat episcopal i els fidels del rei Felip II;

14. cessió al bisbe de Tolosa i al fill de la d'O. de Liliers del territori de Verfeil i de les Bordes, a càrrec del bisbe de prestar al rei el servei feudal que devia als comtes de Montfort; cancel lació de la resta de donacions; Ramon VII haurà de retre homenatge al rei, segons el costum dels barons de França;

15. renúncia a totes les reclamacions a la riba dreta del Roine;

16. reinserció en les seues possessions dels partidaris de l'Església, el rei i els comtes de Montfort;

17. guerra als habitants del comtat que es van negar a sotmetre's, en particular el comte de Foix; qui només podrà ser tractat amb l'aprovació de l'Església; Ramon VII mantindrà durant deu anys les terres confiscades a aquells, amb la destrucció prèvia de les obres defensives; al cap de deu anys, aquestes terres passaran al rei;

18. demolició de les muralles de Tolosa i els valls seran reomplits, segons l'orde del llegat; anivellament de les muralles i ompliment dels valls de les trenta ciutats i castells de Fanjaux, Castelnaudarri, Labécède, Avinyonet, Puylaurens. Saint-Paul, Lavaur, Rabastens, Gaillac, Montaigut, Puycelsi, Verdun, Castelsarrazin, Moissac, Montauban, Montaigut, Agen, Condom, Saverdun, Auterive, Casseneuil, Pujols, Auvillars, Peyrusse, Laurac i cinc altres a elecció de llegat; facultat del comte per fer el mateix en ciutats no fortificades; en cas que els senyors privats s'oposessen a aquesta destrucció, el comte farà servir la força;

19. el comte jura aquestes condicions per a ell i per a tots els seus vassalls; es compromet a fer el mateix jurament als ciutadans de Tolosa i altres habitants de la terra que li quede; en cas d'ofensa per part seua, s'allibera els seus vassalls de tots els deures feudals, si no ha fet cap submissió en quaranta dies, cas en què perdrà el dret per les seues terres; en el jurament s'inclouran les promeses de fidelitat a l'Església $\mathrm{i}$ al rei;

20. lliurament com a penyora al rei de Castell-Narbonés, que el rei mantindrà durant deu anys, amb el poder de fortificar-la, i, amb les mateixes condicions, dels castells de Castelnaudarri, Lavaur, Montaigut, Penne- 
d'Agenais, Peyrusse, Cordes, Verdun i Villemur; durant els primers cinc anys, el compte pagarà 1.500 lliures anuals per al manteniment d'aquests diversos llocs; pot, si l'Església hi està d'acord, destruir els castells de Castelnaudarri, Lavaur, Villemur i Verdun; però la quantitat deguda no es reduirà;

21. lliurament del castell de Penne-d'Albigés abans de començaments d'agost, durant deu anys; el comte assetjarà el lloc, si calia; si no el lliurava en un any, aquest es lliurarà als templers, als hospitalers o a un altre orde religiós a títol d'inalienable i amb el compromís de no fer mai la guerra al rei, tret que siga un mandat de l'Església; si ningú ho vol, es destruirà de dalt a baix; fins al lliurament de la Penne d'Albigés, el rei mantindrà la Penne d'Agenés i el Castel-Narbonés;

22. els ciutadans de Tolosa i els habitants del seus territori que es queden amb Ramon VII són alliberats dels seus juraments al rei i als comtes de Montfort i són alliberats de tota responsabilitat respecte al bisbe i altres prelats.

Pel que ens fa al cas d'aquest estudi, podem remarcar, per ben aspres, diversos aspectes del «relat» que conté aquest Tractat. Ramon VII ha de sotmetre's a l'Església, si vol revertir l'excomunicació de què havia estat objecte; i no és cosa sobre la qual ell mateix puga opinar. Alhora, ha de jurar lleialtat al rei de França, Lluís IX. També ha de demostrar la seua adhesió al nou règim. Aquest nou règim és el mateix que el força a la cessió de la meitat del seu territori a la Corona francesa, especialment el que corresponia als vescomtats de Ramon II Trencavell, feudatari de Tolosa. Bellcaire i Carcassona s'incorporaran directament al domini reial, mentre que el marquesat de Provença ha de ser cedit a la Santa Seu. El comtat de Tolosa perd també els actuals territoris de Gard, Hérault, Drôme, Vaucluse i Aude, encara que pot conservar els territoris de l'Agenais, Rouergue, al nord de l'Albigés i la Quercy inferior. El Tractat estipula el matrimoni de Joana de Tolosa i Aragó, la filla única i l'hereva de Ramon VII, amb un dels germans del rei de França. El designat pel rei serà Alfons de Poitiers, de manera que si el matrimoni no té descendència, totes les seues possessions passaran al domini reial de França -i en són moltes i molt potents aquestes possessions-. I així va ser quan, en 1271 la parella va morir sense fills. Llavors ja havia mort Lluís IX i serà el rei Felip l'Ardit qui heretarà aqueix immens patrimoni que uneix a la seua extensió i riquesa quantitatives envejables, una formidable càrrega qualitativa cultural molt simbòlica atés que es tracta d'alguns dels principals senyorius occitans i aquitans (el rei de França també heretarà el patrimoni aquità d'Alfons) que es compten entre els màxims exponents de la cultura cortés.

Tot això no és prou encara. Ramon VII, a més, s’ha de comprometre a percaçar heretges i també qui els done suport, a fer-se croat i a lluitar durant cinc anys a Terra Santa, i, a més, a reintegrar a l'Església Catòlica el que l'heretgia li va llevar o a compensar-la econòmicament per les pèrdues. La imposició de combatre qui done suport els càtars introdueix un element nociu més en la societat occitana, crea més dissensions internes alhora que aporta efectius -forçats- a la causa de la Croada. Ramon VII ha de satisfer immenses sumes dineràries a la Corona francesa i a l'Església com a compensacions i reparacions de guerra; ell i la resta dels senyors occitans, com a causants culpables, per rebels deslleials i traïdors, a més de confraterinatzadors amb els heretges (quan no directament heretges ells mateixos) que França i el Papa els acusa de ser. Finalment, el comte Ramon VII s'ha de comprometre a fundar una Universitat a Tolosa i a pagar completament les despeses que se'n 
Vicent Martines. La Cançó de la croada contra els albigesos (1r quart del s. XIII) i el Tractat de Meaux-París (1228)

deriven durant 10 anys. Aquesta mesura també llampa atés França així vol controlar el coneixement. Aquesta mesura llampa encara més quant a Tolosa i Occitània en general es compten entre les terres més desenvolupames culturalment de l'Europa catòlica de llavors; no debades Occitània és on es va desenvolupar la cultura i la literatura trobadoresca.

Com a mesura repressiva, el Tractat imposa a Ramon VII desmantellar les imponents fortificacions de diverses ciutats estratègiques, inclosa Tolosa i d'una trentena de castells. Es preserva el potent Castell-Narbonés de Tolosa, que serà cedit al rei de França com a fermança de pau durant 10 anys; així França vol exercir control sobre la població de Tolosa, com segles més tard farà un altre rei francès i de nissaga francesa, a Barcelona, després de la Guerra de Successió i dels Decrets de Nova Planta, i construirà la Ciutadella, amb els canons orientats cap a la ciutat i no per defensar-la de cap enemic exterior. Amb aquesta mesura i les que podem veure en el conjunt del seu articulat, el Tractat conté elements anàlegs al que, segles avenir, trobarem en els ja referits Decrets de Nova Planta (Martines 2020). En definitiva, de la mateixa manera que els Decrets de Nova Planta de Felip V (promulgats entre 1707-1716), aquest Tractat destil la una concepció de la sobirania que es fonamenta en l'execució de la imposició d'un nou ordenament legal i en la derogació del preexistent i propi de cada senyoriu occità. I tot derivat de l'aplicació del «justo derecho de conquista»-com es ben sabut que estableix el Decret de Nova Planta per derogar els furs dels regnes d'Aragó i València, el 29 de juny de 1707-:

justo derecho de la conquista que de ellos han hecho últimamente mis armas con el motivo de su rebelión; y considerando también que uno de los principales atributos de la soberanía es la imposición, y derogación de las leyes» (Recopilación 1805, t. III, 1.III, 1. I)

En definitiva, aquest Tractat ateny el control de les principals facetes del govern: obliga els senyors occitans a declarar i acreditar amb fets -lluita activa en pro de les forces Croades- la seua «nova» adhesió al nou règim polític, i a l'Església. Controla el patrimoni dels senyorius i en subverteix la transmissió i successió. Afecta les finances dels senyorius i crea institucions de control del coneixement. La d'aquest Tractat, com tampoc no la dels Decrets de Nova Planta referits, no es tracta d'una concepció del poder ni de l'execici del govern en pro de l'interés general i bé públic, que ens podríem trobar en autors com Eiximenis, i abans en Sant Tomàs d'Aquino o Llull, o després fins i tot en Maquiavel, o en Vives i Sant Tomàs Moro (Roig-Vila 2015; Roig-Vila \& Merma \& Gavilán-Martín 2020).

Tot això plegat accentua més els efectes del Tractat de Meaux-París quant a la despossessió dels senyors occitans dels seus senyorius que perpetra la Corona francesa. No sols afecta Tolosa, sinó també tot Occitània. A més, el comtat de Tolosa era de referència principal, exercia una mena d'irradiació de d'identitat col lectiva dels occitans. En molts dels enfrontaments i batalles que reporta la Cançó de la Croada, les forces occitanes entren en combat al crit de «Tolosal». En virtut del Tractat de Meaux-París, França s'arroga el poder per, si (li) convé, alterar o subvertir les línies successòries dels senyorius. Així, el comte de Tolosa amb la meitat d'extensió territorial romanent, en haver-ne desposseït França el comte 
Vicent Martines. La Cançó de la croada contra els albigesos (1r quart del s. XIII) i el Tractat de Meaux-París (1228)

legítim i, a sobre, haver-lo excomunicat l'Església (28-01-1226), i , per tant, abocat a fer guerrilla a les forces d'ocupació, ha d'acceptar que el comtat passe a la seua filla en vida d'ell. Passa a la seua filla, Joana de Tolosa. A sobre, el seu pare l'ha de lliurar al rei de França perquè ell decidesca amb quin dels seus germans la casarà. Lluís IX elegeix son germà Alfons de Poitiers com a marit de Joana de Tolosa. No es tranquil litzador, als efectes polítics occitans, que qualsevol dels possibles elegits pel monarca francès haja de ser un dels seus germans, prínceps de França de sang reial. No és tranquil litzador perquè això rebla, al remat, la subversió irreversible de la transmissió -més d'hora que tard- de la resta del senyoriu en favor de la Corona francesa i, per tant, en consumarà la despossessió.

\section{Objectiu del Tractat de Meaux-París: emparar-se de la terra i desposseir els legítims} senyors, que esdevenen faïdits.

La Corona francesa pretén reblar l'ocupació, annexió i incorporació dels territoris occitans al patrimoni reial. A més, les successives cessions territorials a la Corona francesa causen contínues despossessions (desnonaments, inclosos) de cavallers i senyors «menors» $\mathrm{i}$ feudataris dels grans senyors feudals desposseïts en primera instància. Aquestes despossessions «menors», però ben nombroses, alteren la història local, la trama de relacions familiars, laborals i de dependències existents que constituien fins llavors el teixit social del país, el dia a dia del poble -derrotat i ara, a sobre, desposseït. La substitueixen pel teixit social d'aquells altres, forasters, als quals els són adjudicades arbitràriament les propietats desnonades. Els desposseïts, grans senyors i petits, són els anomenats faïdits, els quals tenen a més, tradició literària i cultural atés que entre aquest estrat de població, culta, benestant, hi havia trobadors i, en general, el que ara en diríem productors i consumidors culturals. Això no és una qüestió menor mai, i menys encara en l'Occitània de llavors. Aquestes despossessions en cascada, afecten directament el medi ambient i el genoma (la «intelligentsia») de la Cultura i la literatura cortés i del conreu de la llengua occitana. La comtessa Alix (Alícia) de Montmorency (Cawley 2020), muller del cabdill Simó de Montfort, durant l'ocupació de Tolosa durant la Croada, vol avisar el seu marit que Tolosa ha caigut en mans del comte legítim i vol requerir-lo perquè marxe sobre Tolosa per recupera-la per a la causa croada. A l'efecte, segons ens diu la Cançó de la Croada, la comtessa: «La comtessa cridà un escuder poliglot / que vaja al pas, amble i al trot més ràpid que cap dimoni» (1.183). Els ocupants no saben occità, ni tenen en el seu «estat major» personal que en sàpiga.

Els faïdits són foragitats sense dret a portar res amb ells, literalment nus o amb una escassa roba interior (Vegeu la Figura 5). El Tractat de Meaux-París va reforçar el sistema repressiu contra els càtars (Buffetaut 2016). Tinguem en compte que aquesta, la lluita contra els heretges càtars va ser la cortina de fum, l'excusa, la versió i imatge oficial del per què de la Croada que va envair Occitània; la primera croada contra cristians en Occident (Léglu \& Rist \& Taylor 2014; Grange 2014; Pegg 2008). Pel Tractat de Meaux-París es veu que realment era una guerra de conquesta. 


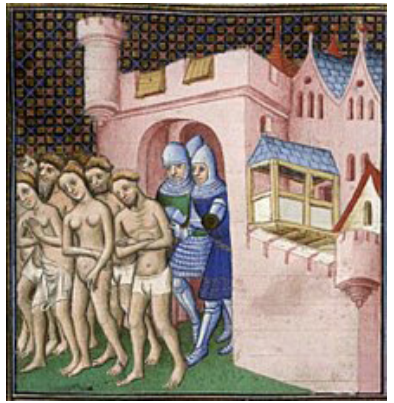

Figura 5. Habitants de Carcassona foragitats, faïdits, de fet nus del tot, sense res, pels croats. Grandes Chroniques de France, British Libray, BL Cotton MS Nero E II

El rei Lluís IX de França hi va tenir molt a fer. Després, aquest serà el Sant i era fervent creient, molt obedient tota sa vida als designis de la seua intel ligent mare, Blanca de Castella, gran facilitadora de la creació i creixença de l'Orde dels Predicadors, que va ser creada per Sant Doménech de Guzmán ex professo per erradicar amb prèdiques l'heretgia càtara. Lluís IX creia molt en l'ideal integrista religiós de croada. Tant és així, que «prendre la creu», fer-se croat i servir com a tal, era un dels articles imposats pel Tractat de Meaux-París (art. 10); la croada a «Outremer» esdevé un molt bon mitjà per embarcar-hi -literalment- la poderosa i destra població senyorívola occitana i compromete-la (a la força) en una mampresa llunyana, d'alt risc, que, a més d'allunyar-la de casa, podia esvair ànsies de revolta. A més de continuar la Croada contra els albigesos -que tan productiva resultava per al patrimoni reial-, Lluís IX va promoure'n dues altres més: una a «ultra man», la Setena Croada, a Palestina i Egipte (1248-1254), saldada amb un nou fracàs dels «francs» sobretot per desconeixença de la política i món d'Orient Mitjà (Joinville 1995); i l'altra, la Vuitena, al Nord d'Àfrica, a Tunis (1270). Aquesta croada, també va ser un fracàs quant als seus objectius (Hélary 2016; Le Goff 2016). A més, va significar un gran desastre per a la monarquia francesa: mort del rei Lluís IX (†25-08-1270) per l'epidèmia de dissenteria que va assolar el seu campament, ${ }^{3}$

\footnotetext{
3 Aqueixa és la hipòtesi tradicional sobre la mort de la majoria dels caiguts de la Vuitena Croada. Tot i això, recerques fetes en 2018-2019 sobre les relíquies de Sant Lluís de França (després del seu traspàs, se li va aplicar el mos tentonicus) permeten afirmar als investigadors que ben provablement patia d'una forma severa de bilharsiosi que indicaria una important presència de schistosomes mascles adultes (Schistosoma haematobium) en els ossos del Sant. Tot i que el paràsit és present a tot el Nord d’Àfrica, el breu termini transcorregut entre el desembarcament de les forces croades a Tunis i l'òbit del rei, vol dir que aquest devia haver-se infectat abans del seu desembarcament a Tunis. Si la infecció s'hagués produït a Tunis estant, el paràsit no hauria tingut prou temps, abans del decés del rei, per desenvolupar-se fins a la fase adulta i fer evidents els símptomes de la malaltia. Provablement, segons aquesta recerca, la infecció es produí quan el rei va ser a Damietta, al delta del Nil, al 1250, o durant els quatre anys següents, en què va ser a Acre, Cesarea o Jaffa, durant la Setena Croada. El paràsit és present també en aqueixa part de la Mediterrània. Sembla que no va ser la causa directa o última de la mort, però sí que li degué causar un quadre de gran feblesa, i això és compatible amb l'estat de salut general que mostra el rei durant els darrers anys de la seua vida. En definitiva: «These results show that the French King was infected byschistosomiasis [...] Reasonably, Schistosoma did not play a direct role in the mechanism
} 
d'un fill seu (príncep Joan Tristany, †3-08-1270), del germà del rei, Alfons de Poitiers (†21-081271) i la dona d'aquest, Joana de Tolosa (†25-08-1271), comtes de Tolosa, que moriran al castell de Corneto (Tarquinia, prop de Viterbo) en el viatge de tornada a França com a resultat de la malatia contreta en la croada; morta en un accident en el viatge de tornada de la reina consort de França, Isabel d'Aragó i Hongria (†28-01-1271), que va perdre, a més, la criatura de la qual estava embarassada del 6é mes.

El Tractat de Meaux-París forçava els occitants a jurar lleialtat a la Corona de França -sots pena d'esdevenir faïdits i l'exili, o encara pitjor- i a prendre part activa en la lluita, persecució i repressió contra l'heretgia càtara i a fer la guerra a qui els defensés. Això va fer que aquesta repressió que, fins llavors, havia estat en mans dels oficials de la inquisició i els efectius croats forasters, entrara en una fase més pròpia d'un enfrontament civil, entre els propis i iguals, amb un afany extremat per les emocions encontrades i, alhora, per la por -molt real- de perdre les propietats, els senyorius i la vida. No de manera immediata, però paulatinament i indeturada, el catarisme, perd base social.

Això provoca una veritable diàspora, un veritable èxode entre els occitans, naturals i alhora senyors legítims de les seues terres. A Occitània estant no hi havia quarter possible. Per això

of death for Saint-Louis, whose exact cause of death remains unknow» (Charlier \& Bouchet \& Weil \& Bonnet 2016; Faure 2016). Ens completa una mica més el problemàtic quadre mèdic de Sant Lluís de França la consideració que va patir de malària des de 1242 (infectat a França) i de malària cerebral des de 1244. Sembla que no hi hagué una epidèmia de pesta entre les forces croades, almenys no tan gran per causar desorganització entre les seues forces, atés que van poder fer un tracte molt avantatjós, a Tunis estant, per pactar la retirada. Quant a Sant Lluís es podria afirmar: «SaintLouis therefore, probably suffered from chronic malaria associated with other infections.» (Faure 2016).

Aqueixa infecció patida pel rei de malària i després malària cerebral, pot ser ben bé explicació (o causa) del seu estat de salut general feble des de la campanya de Santoinge, (1242-44). Llavors, en auxili del seu germà, Alfons de Poitiers, va fer front amb èxit encara que amb greu esforç a una entesa entre Huc de Lusignan, Enric III d'Anglaterra i Ramon VII de Tolosa. En aquesta campanya, el rei es va fer malalt molt greu ja en 1242, i va ser a punt de morir (desembre de 1244). Hom explica la seua recuperació com si fóra un miracle i subratlla el clim providencialista del fet que, en el moment de recobrar l'esme, el rei va expressar el seu vot de fer-se croat (en la que serà la Setena, i, per l'escàs resultat d'aquesta, encara en la Vuitena croada). Ens n’ha quedat constància iconogràfica del moment. Vegeu, p.e., Figura 6.

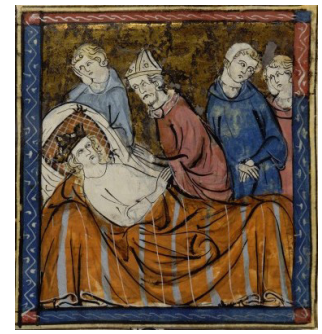

Figura 6: Lluís IX de França en el moment fer vot de croada. Histoire d’Outremer, Bibliotheque nationale de France, Fr. 9083 f. $320 \mathrm{v}^{\mathrm{o}}$. 
molts van refugiar-se especialment a la Corona d'Aragó, a la cort de Jaume I, a les terres pirinenques del vessant sud; també a la Savoia transalpina, Ligúria i Sicília. Van estrendre, encara més, la cultura cortés trobadoresca, just quan a casa seua ja havien perdut les bases efectives, objectives, vitals, econòmiques, demogràfiques, culturals i lingüístiques que havien produït l'excelsa creació cultural que és la cultura cortés, és a dir, la literatura trobadoresca.

\section{Alfons de Poitiers, primer gran beneficiat pel Tractat Meaux-París, i l'ars de la negociació de Ramon VII i els cònsols de Tolosa}

Alfons de Poitiers va ser ben bel ligerant anticàtar. Va ser, per tant una molt bona eina quant a la política d'apropiació dels senyorius occitans (del comtat de Tolosa) més en concret a la Corona francesa. Ell, cap a 1250, germà del rei de França i, per tant, figura molt rellevant, va escriure una carta al papa Innocenci IV per sol licitar-li l'emissió d'una butlla per una nova croada contra els càtars. La lletra es conserva en la seua versió d'esborrany i té més valor encara perquè al verso n'hi ha un dibuix que mostra un heretge (càtar) sent cremat a la foguera viu, nu i lligat a una estaca. No se sap si aqueix dibuix ben eloqüent-encara que força esquemàtic i, per tant, no atribuible a un il luminador ni expert ni professional- fou fet també de la mateixa mà d'Alfons de Poitiers, llavors també comte de Tolosa des de 1229. Tanmateix, que aqueix dibuix -i més encara tan senzill, i no resultat d'una complexa i acurada realització per mans expertes- es trobe en el mateix suport escriptori de l'esborrany de la carta es força indicatiu del caire innegablement integrista (religiós) del redòs més elevat de l'aristocràcia francesa que encara volia una nova croada per acabar de reblar l'emparament dels senyorius occitans (vegeu Figura 7).

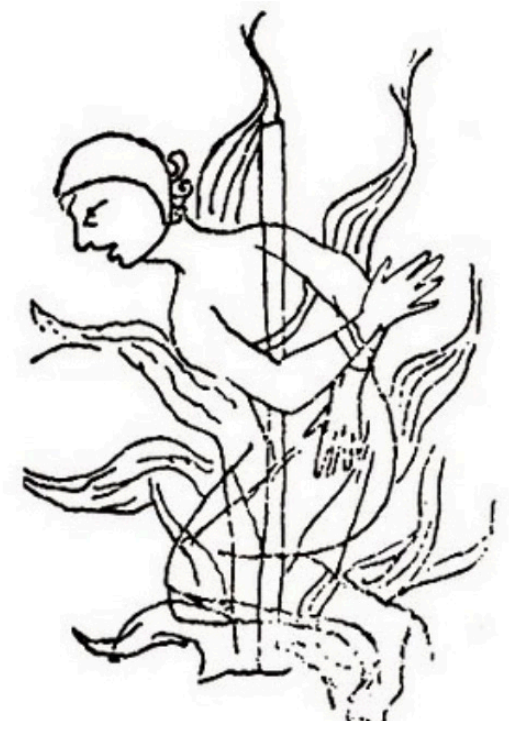

Figura 7: dibuix que mostra un heretge (càtar) sent cremat a la foguera viu, nu i lligat a una estaca. És el verso d'un esborrany de carta d'Alfons de Poitiers al Papa Innocenci IV en què li demana l'emissió d'una butlla per una nova croada anticàtara a Occitània. Archives nationals, "Grands documents de l'histoire de France; Florilège”, N notice 00000192, Fonds MUS, Cote AE/II/257 (Cote origine J428/1). 
Alfons de Poitiers encarna la política d'apropiació per part de la Corona francesa dels grans senyorius occitans, precisament en aplicació del Tractat de Meaux-París: a la fi reuneix en el seu haver els títols i possessions corresponents de comte (consort) de Tolosa, marqués de Provença (consort), d'Aubèrnia, a més dels comtats de Santoigne i de Poitiers. En definitiva, reuneix en la seua persona 3 dels senyorius més importants d'Occitània i dos dels senyorius més importants d'Aquitània, és a dir, algunes de les zones més riques i històricament més remarcables quant a la cultura trobadoresca, i totes revertiran al patrimoni reial francès en el moment del seu òbit, en aplicació del Tractat de Meaux-París.

En aquest sentit, val a dir que Alfons de Poitiers rep Tolosa i el marquesat de Provença per ser consort de la filla de Ramon VII, Joana de Tolosa i Aragó. Ella té llinatge d'Aragó perquè la seua mare, Sança d'Aragó, era la tercera filla del rei Alfons el Trobador, primer rei de la Corona d'Aragó. Aquest va portar a la pràctica un intel ligent pla de pactes i matrimonis «d'estat» a fi i efecte d'estendre i afermar pacíficament l'expansió de la Corona d'Aragó al nord dels Pirineus. De fet, una germana immediatament més gran que Sança, Elionor d'Aragó, la 4a filla de son pare, ja era casada, des de 1202, amb el pare del seu marit i predecessor seu en el comtat de Tolosa, Ramon VI -qui havia tingut son fill d'un matrimoni anterior al d'Elionor-. La seua filla Sança, tia de Jaume I el Conqueridor, serà essencial en aquest pla: Alfons el Trobador concerta el matrimoni de la seua filla Sança amb l'hereu del comtat de Tolosa i del marquesat de Provença. Tot un doble triomf diplomàtic, i ben indicatiu de com era d'important el poder percebut de la Corona d'Aragó en aquelles riques i cultes terres. En aqueix pla d'expansió dinàstica i territorial, Alfons el Trobador aconsegueix el poderós comtat de Provença i li’l concedeix primer al seu 5é fill, Sanç d'Aragó, encara que després li’l reassigna al seu 3r fill, Alfons Berenguer d'Aragó. D’aquesta manera, la Corona d'Aragó s'assegurava estratègicament la continuïtat geogràfica dels seus territoris sudpirinencs, amb els principals senyorius occitans cap a l'interior i per la costa, fins a Ligúria (Gènova) i la Savoia piemontesa (Demotz 2008). Interessava contactar amb Savòia -s'assegurava profunditat estratègica fins als Alps i a Savòia li interessava contactar amb la Provença vinculada a la Corona d'Aragó -l'accés a la mar i un «estat» no gens irrellevant- (Demotz 2000). Per això Alfons Berenguer comte de Provença va encastar el llinatge amb els comtes de Savoia, amb el matrimoni amb Beatriu de Savoia (Cawley 2020). L'arc de la Mediterrània ja quasi es completava, fins que la croada contra els càtars tot ho va estroncar i va aplicar una estratègia d'expansió de la Corona de França a Occitània antitètica respecte a la de la Corona d'Aragó: a la política de pactes matrimonials i aliances, França oposa la imposició per la força de matrimonis que impliquen l'apropiació de senyorius, després (o en el transcurs) d'una croada ferotge.

La Corona de França, a través d'Alfons de Poitiers, i amb el Tractat de Meaux-París, procura imposar un govern reial centralitzat a Tolosa (Gardner 2006: 426). La brutalitat de la croada i la ferrenya despossessió, però, no van ser panacea perquè l'administració francesa es trobés un camí de roses a Tolosa i, per extensió a la resta de senyorius occitans que patiren la croada. La Corona francesa i els seus representants a Occitània, amb Alfons de Poitiers com a cap visible, van haver 
Vicent Martines. La Cançó de la croada contra els albigesos (1r quart del s. XIII) i el Tractat de Meaux-París (1228)

de negociar, i no poc. Els cònsols de Tolosa són força renuents a acceptar de grat les imposicions d'Alfons de Poitiers i l'obliguen a haver de negociar com a eina quotidiana de govern. Els cònsuls de Tolosa són força destres i hàbils i no actuen de manera descoordinada del seu comte legítim, Ramon VII, qui, tot i que faïdit, no els va desemparar mai ni va abandonar mai la idea de redreçar la situació, fins i tot, per la via armada. Una prova ben il lustrativa de la manera en què els cònsuls de Tolosa sabien fer valdre la seua posició i forçaven a la negociació Alfons de Poitiers hi i Lluís IX és quan aquest volia llançar la Vuitena Croada (contra Tunis, 1270). La Corona francesa necessitava liquiditat per respondre a les necessitats enormes que requeria aqueixa croada $i$ va demanar a Tolosa, a través d'Alfons de Poitiers, els fons necessaris; al cap i a la fi, el Tractat de Meaux-París estipulava que els senyors occitans que volgueren demostrar la seua adhesió al «nou règim» derivat de la Croada contra els albigesos, havien de prendre la creu i lluitar contra l'infidel. Els cònsols de Tolosa van aprofitar l'avinentesa per demanar que Alfons de Poitier confirmés els drets i privilegis històrics de Tolosa. A l'efecte, van presentar a Alfons de Poitier una mena de memorial de peticions $i$ aquest hi va estar d'acord. Aqueix acord va permetre que els cònsols de Tolosa lliuraren els fons necessaris per rellançar la croada el 1271, malgrat que el rei Lluís IX ja hi havia mort en agost de l'any anterior, i va facilitar que el seu seguici tornés a París. Ja hem vist supra que aqueixa croada va ser un fracàs militar i un desastre per a la monarquia francesa per les morts que va causar en la persona del rei Lluís IX mateix, i rellevants membres de la família reial (inclòs Alfons de Poitier i Joana de Tolosa). Als efectes nocius d'aqueixa croada per a la Corona francesa, hauríem d'afegir el triomf que va significar per als cònsols de Tolosa els drets que França els va haver de reconèixer perquè accediren a concedir els fons perquè tingués lloc aqueixa expedició armada.

A més, aqueixa avinentesa va fer que els cònsols de Tolosa prengueren encara més consciència, si més no, de la força que tenien. Felip III, successor de Lluís IX, que passa per ser «le premier souverain à établir avec succés les structures jurídiques septentrionales et le gouvernement capétien» (Gardner 2006: 426), també va haver de negociar molt sovint amb Tolosa. I també el successor de Felip III. Felip IV (1285-1314), ateses les mampreses bèl liques en què s’havia compromés a Flandes, necessita novament fons i liquiditat que sols podia concedir-li Tolosa. Els cònsols de Tolosa van aprofitar novament i molt bé l'ocasió, per causa d'aqueixes necessitats o febleses del monarca francés en política exterior, per negociar i aconseguir més drets encara d'aquells que la Corona francesa els havia arrabassat amb el Tractat de Meaux-París: «La segneurie resta finalment una entité négociée non par générosité ou faiblesse capétienne, mais parce que les Toulousains et leurs consuls l'entendaient ainsi, et qu'ils étaient prompts à utiliser à leur avantatge les préoccupations jurídiques ou militaires de leurs souverains» (Gardner 2006: 429). Els de Tolosa van obtenir grans victòries en aquests processos de negociació i se'n va derivar una praxi de la senyoria, del govern, diferent a la que pretenia la Corona francesa.

Aquest procés de negociació forçada per la ferrenya determinació i destresa curial dels occitans i les febleses/necessitats de la Corona francesa esdevé una mena de fase «freda» de l'enfrontament dels senyorius occitans amb els croats dels Montfort i la Corona mateixa, especialment quant al

SCRIPTA, Revista internacional de literatura i cultura medieval i moderna, núm. 15 / juny 2020 / pp. 16 - 37 ISSN: 2340-4841 · doi:10.7203/SCRIPTA.15.17552 
comtat de Tolosa per raó de la magnitud quantitativa de la seua economia i la qualitat de la seua referencialitat identitària en el context occità (Gardner 2005). De fet, les operacions militars de la Croada contra els albigesos no havien cessat en absolut, ni per la voluntat dels croats, ni per la resistència dels faïdits, que no renuncien a «recobrar les terres que foren dels seus pares» (Cançó de la Croada, 1. 143), és a dir, literalment, 'la seua pàtria'. En l'ars de la negociació occitana oposat a la imposició per dret de conquesta de la Corona francesa, tenim un nou teatre d'operacions de la lluita que s'hi dona entre dues identitats col lectives diferents, jurídicament, fiscalment i cultural: un Nord, representat per la monarquia francesa capeta que, amb Lluís IX inicia el camí cap a la monarquia autoritària i, segles avenir, absolutista; i un Sud, Occitània, que, malgrat ser vassalla de la Corona francesa i encara també de la Corona d'Aragó, és un mosaic de senyorius autònoms (Gardner 206: 429).

\section{Conclusió}

Hem analitzat els mecanismes de la construcció del relat, sota diversos punts de vista, de la Croada contra els albigesos i la despossessió d'Occitània per la Corona francesa en el transcurs d'aqueixa cruel campanya militar ( $1 \mathrm{r}$ terç del segle XIII). Hem analitzat dues fonts textuals que són testimonis d'excepció dels fets i de la construcció mateixa d'aqueix relat, a través de la mimesi historiogràfica en un cas, la Cançó dela Croada contra els albigesos, i, en l'altre, del formalisme d'un text jurídic (document històric, pròpiament dit) del més alt rang, el Tractat de de Meux-París (1229), signat pels màxims representants de les dues contraparts. De fet, bona part dels personatges del text literari, que hi són perquè protagonitzen els fets de la Croada (defensors/atacants), són els protagonistes (i signataris o testimonis de la signatura) del Tractat. Hi ha també qui es beneficia dels efectes del Tractat. Aquest Tractat demostra, com establirem en la nostra anàlisi, que la Croada va ser en realitat una vera guerra de conquesta amb l'objectiu de la despossessió d'Occitània i el desplaçament de la Corona d'Aragó, que ha de reorientar la seua política d'expansió cap al sud dels Pirineus i la Mediterrània. 
Vicent Martines. La Cançó de la croada contra els albigesos (1r quart del s. XIII) i el Tractat de Meaux-París (1228)

\section{Bibliografia}

Albareda i Salvadó, J. (2010) La Guerra de Sucesión de España (1700-1714), Barcelona, Editorial Crítica.

Alvira Cabrer, M. (2008) Muret 1213: la batalla decisiva de la cruzada contra los cátaros, Barcelona, Ariel, 2008.

—. (2014) «Tòpics i llocs comuns d'una batalla decisiva: Muret, 1213», Butlletí de la Societat Catalana d'Estudis Històrics, 25, págs. 19-43.

(2015) «Diferencias interpretativas y problemas militares. La batalla de Muret en la historiografía contemporània», dins Aa. Vv., La encrucijada de Muret, Sevilla, Sociedad Española de Estudios Medievales: Archivos y Publicaciones Scriptorium, pp. 9-88.

- (2016a) «La Cruzada contra los Albigenses: historia, historiografía y memòria», Clío \& Crímen: Revista del Centro de Historia del Crimen de Durango, 6, pp. 110-141.

—..(2016b) «Non prevaluit consilium Achitophel: Debates y decisiones del Cuarto Concilio de Letrán sobre la Cruzada Albigense», Revista Chilena de Estudios Medievales, 9, pp. 27-62.

—. (2019) «Jaque mate a la «gran corona de Aragón»: la batalla de Muret». Desperta Ferro, 56 [Dedicado a: La cruzada contra los cátaros (I), 1209-1215], pp. 38-46.

Balard, M. \& Genêt, J.-Ph. \& Rouche, M. (1994² [1989]) De los bárbaros al Renacimiento, Madrid, Akal, pp. 191-194 [«Las heregías y su represión»].

Benito i Monclús, P. (2019) «Pedro II el Católico y Occitania: la gestación de un ambicioso proyecto político». Desperta Ferro, 56 [Dedicado a: La cruzada contra los cátaros (I), 1209-1215], pp. 2026.

Bordonove, G. (1991) La Tragédie cathare, Paris, Pygmalion.

Buffetaut, Y. (2016) Les cathares: et la croisade contre les Albigeois, Louviers, YSEC Editions.

Cassignol, É. (2006) France d'oïl contre France d'oc : la première guerre franco-française, 1209-1249, La Compagnie littéraire-Brédys, Paris.

Cawley, Ch. (2020) «Medieval Lands: Provence - Kings, counts», dins Medieval lands: A prosopography of medieval European noble and Royal famílies, Foundation for Medieval Genealogy $<$ https://fmg. ac/projects/medlands $>$ [consulta 20-02-2020]

Charlier, Ph. \& Bouchet, F. \& Weil, R. \& Bonnet, B. (2016) «Schistosomiais in the mummified viscera of Saint Louis (1270 AD)», Forensic Sci Med Pathol, Mar; 12(1):113-4. doi: 10.1007/s12024-015-9722-4 .

Cox, E. L. (2015 [1974]) The Eagles of Savoy: The House of Savoy in Thirteenth-Century Europe, Princeton, Princeton University Press.

Cressier, P. \& Cuenca, V. S. (coords) (2014) Las Navas de Tolosa 1212-2012. Miradas cruqadas, Jaén, Universidad de Jaén. 
Vicent Martines. La Cançó de la croada contra els albigesos (1r quart del s. XIII) i el Tractat de Meaux-París (1228)

Dedieu, J.-P. (2000) «La Nueva Planta en su contexto. Las reformas del aparato del Estado en el reinado de Felipe V», Manuscrits. Revista d'Història Moderna, 18, pp. 113-139.

Demotz, B. (2000) Le comté de Savoie du XIe au XVe siècle: Pouvoir, châtean et État an Moyen Âge, Genève, Slatkine.

——. (2008) Les Principautés dans l'Occident Médiéval: À l'origine des régions, Turnhout, Brepols.

Faure, E. (2016) «The infections of Saint-Louis: possible involvement of malària», Forensic Sci Med Pathol 12, 121. https://doi.org/10.1007/s12024-015-9732-2

Furió, A. (1995) Història del País Valencià, Valencia, Edicions Alfons el Magnànim.

Gardner, Ch. (2005) «Heretics of Lawyers? Propaganda and Toulousan Indentity through the Albigesian Crusade», dins Hayes-Healy, S. (ed.), Medieval Paradigms. Essays in Honor of Jeremy Duquesnay Adams, Nova York, EUA / New Hampshire, Anglaterra, Palgrave Macmillan, pp. 115-138.

- (2006) «Négocier le pouvoir: Toulouse et son gouverneement sous les Capétiens (vers 12001340)», Annales du Midi, 255, pp. 425-249.

Gascón Chopo, C. (2015) «Muret, un hito en la sedentarización del catarismo en Cataluña», Aa. Vv., La encrucijada de Muret, Sevilla, Sociedad Española de Estudios Medievales : Archivos y Publicaciones Scripturium, pp. 149-162.

Grange, H. (2014) «[ressenya de Léglu, C., Rist, R \& Taylor, C.] The Cathars and the Albigensian Crusade: A Sourcebook», French Studies, Volume 68, Issue 4, October 2014, Pages 536-537, https://doi.org/10.1093/fs/knu201

Hélary, X. (2016) La dernière croisade, Paris, Perrin.

Jiménez, P. (2015) «Muret y la consolidación de un frente disidente transpirenaico», dins Aa. Vv., La encrucijada de Muret, Sevilla, Sociedad Española de Estudios Medievales: Archivos y Publicaciones Scripturium, pp. 177-194.

- (2019) «La herejía de los cátaros», Desperta Ferro, 56 [Dedicado a: La cruzada contra los cátaros (I), 1209-1215], pp. 14-18.

Joinville, J. de (1995) Vie de Saint Lonis, ed. de Jacques Monfrin, París, Classiques Garnier.

Lambert, D. (1986) La herejía medieval.Movimientos populares, de los bogomilos a los husitas, Madrid, Taurus.

Langlois, G. (2001) Olivier de Termes, Le Cathare et le Croisé (vers 1200-1274), Toulouse, Privat.

Laval, P. (2000) Los cátaros. Madrid, Crítica.

Laveaga, G. (2006) El sueño de Inocencio. Mexico, Martinez Roca.

Le Goff, J. (1996) Saint Louis, París, Callimard.

Léglu, C. \& Rist, R. \& Taylor, C. (2014) The Cathars and the Albigensian Crusade: A Sourcebook, Abingdon-on-Thames, Londres / New York, Routledge.

SCRIPTA, Revista internacional de literatura i cultura medieval i moderna, núm. 15 / juny 2020 / pp. 16 - 37

ISSN: $2340-4841 \cdot$ doi:10.7203/SCRIPTA.15.17552 
Vicent Martines. La Cançó de la croada contra els albigesos (1r quart del s. XIII) i el Tractat de Meaux-París (1228)

Lippiatt, G.E.M. (2017) Simon V of Montfort and Baronial Government, 1195-1218, Oxford, University Press Scholarship-Oxford Scholarship Press.

—. (2019) «Eia, Christi milites!: La cruzada de los barones de 1209». Desperta Ferro, 56 [Dedicado a: La cruzada contra los cátaros (I), 1209-1215], pp. 28-37.

Macé, L. (2006) «Une belle synthèse sur la Provence du XIIIe siècle», Annales du Midi: revne archéologique, historique et philologique de la France méridionale, 118, 255, pp. 471-474.

. (2015) «Avant et après Muret: le Midi de la France au tournant du XIIIe siècle (1195-1222)», dins Aa. Vv., La encrucijada de Muret, Sevilla, Sociedad Española de Estudios Medievales: Archivos y Publicaciones Scripturium, pp. 195-210

- - (2019) «Una cruzada contra los malos cristianos». Desperta Ferro, 56 [Dedicado a: La cruzada contra los cátaros (I), 1209-1215], pp. 6-12.

Martines, V. (2018a) «Diàlegs interdisciplinaris entre text $\mathrm{i}$ imatge. Pintar amb paraules en Tirant lo Blanch de Joanot Martorell i en la Tragèdia de Caldesa de Joan Roís de Corella: ěxф@ $\alpha \sigma ı 5$,

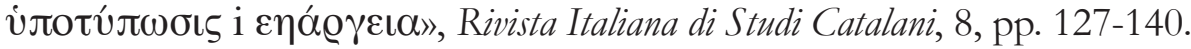

(2018b) «Identitats literàries que milloren les reals. Mimesi i historiografia: lligams entre cavalleria literària, historiografia i espais en la (de)construcció de la identitat en les lletres catalanes medievals (35-66)», Zeitschrift für Katalanistik, 31, pp. 35-66.

- (2020) «The Treaty of Meaux-Paris (1229), an Early 'Decret de Nova Planta'. Consequences of the «Law of Conquest» for the Crown of Aragon», dins Cortijo, A. \& Martines, V., History of Catalonia, Hershey, Pennsylvania, IGI Global, pp. En premsa.

Martines, V. \& Ensenyat, G. (eds.) (2003) Guilhem de Tudela \& Anònim, La Cançó de la Croada contra els albigesos, Barcelona, Proa.

Marvin, L.W. (2008) The Occitan War: A Military and Political History of the Albigensian Crusade, 12091218, Cambridge, UK, Cambridge University Press.

(2019) «Los más temibles asedios, 1209-1215. Desperta Ferro, 56 [Dedicado a: La cruzada contra los cátaros (I), 1209-1215], pp. 52-57.

Mussons Freixas, A.M. (2015), «La voz de los trovadores antes y después de la batalla de Muret», dins Aa. Vv., La encrucijada de Muret, Sevilla, Sociedad Española de Estudios Medievales: Archivos y Publicaciones Scripturium, pp. 239-258.

Paul, J. (2007) «La paix de Saint-Gilles et l'exercice du pouvoir», dins Carozzi, Cl. \& Taviani-Carozzi, H. (eds.) Faire l'événement au Moyen Âge, Aix-en-Provence, PUP, pp. 147-168.

Pécout, T. (2004) Raymond Bérenger V (1209-1245). L'invention de la Provence, Paris, Perrin.

Pegg, M. G. (2008) A Most Holy War. The Albigensian Crusade and the Battle for Christendom, New York, Oxford University Press.

Pérez Aparicio, C. (1981) De l’alçament maulet al triomf botifler, Valencia, Tres i Quatre. 
Vicent Martines. La Cançó de la croada contra els albigesos (1r quart del s. XIII) i el Tractat de Meaux-París (1228)

Quintilianus, Institutio Oratoria, IX, 2, 40. < $\underline{\text { http://perseus.uchicago.edu/perseus-cgi/citequery3.pl }}$ ?dbname $=$ LatinAugust $2012 \&$ query $=$ Quint. $\% 209.2 .40 \&$ getid $=0>\quad$ [consulta: $25-02-2020$ ]

Recopilación (1805). Recopilación de las leyes de España dividida en XII libros en que se reforma la Recopilación publicada por el Señor Dos Felipe II en el año 1567, reimpresa últimamente en el 1775, y se incorporan las pragmáticas, cèdules, decretos, órdenes y resoluciones Reales, y otras providencias no recopilades y expedides hasta el de 1804, mandada formar por el Seños Don Carlos IV, Madrid.

RLALTO. Repertorio informatizzato dell'antica letteratura trobadorica e occitana (Università degli Studi Federico II di Napoli) < http://www.rialto.unina.it/BdT.htm > [consulta: 19-02-2020].

Roig-Vila, R. (2015) «Elogio de la palabra en la formación y enseñanza en algunos clásicos de la literatura catalana medieval: Llull, Eiximenis y San Vicente Ferrer», Crítica Hispánica, 37, 1, pp. $97-116$.

Roig-Vila, R. \& Merma, G. \& Gavilán-Martín, D. (2020) «Proposals for social pedagogy and the best political practices. Contribution from the Crown of Aragon: Francesc Eiximenis and his Regiment de la cosa pública», dins Cortijo, A. \& Martines, V., History of Catalonia, Hershey, Pennsylvania, IGI Global, pp. In press.

Roquebert, M. (2001) L'épopée cathare, París, Privat.

- - (2006a) L'Epopée cathare, I. L'invasion 1198-1212, París, Perrin.

—. (2006b) L'Épopée cathare, II Muret ou la dépossession 1213-1216, París, Perrin.

- (2007) L'Epopée cathare, 3. Le lys et la croix 1216-1229, París, Perrin.

—. (2010) Simon de Montfort, París, Perrin.

Setton, K. M. (Gen. Ed.) \& Wolff, R. L. \& Hazard, H. W. (eds.) A History of the Crusades: The Later Crusades, 1189-1311, Madison, Milwaukee / Londres, University of Wisconsin Press, 1969, pp. 299-320.

Smith, D. J. (2015) «Muret y las limitaciones del poder del papado», dins Aa. Vv., La encrucijada de Muret, Sevilla, Sociedad Española de Estudios Medievales: Archivos y Publicaciones Scripturium, pp. 2 75-286.

. (2019) «La ira de Dios: el pontífice Innocencio III y la cruzada albigense». Desperta Ferro, 56 [Dedicado a: La cruzada contra los cátaros (I), 1209-1215], pp. 48-51.

Zerner, M. (1979) La croisade albigeoise, París, Gallimard. 